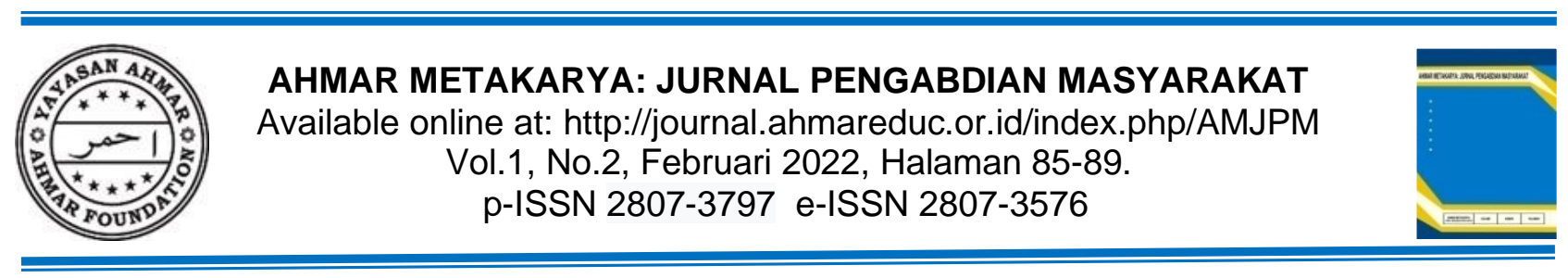

\title{
Edukasi Resusitasi Jantung Paru Pada Masyarakat Kabupaten Belitung
}

\author{
Ashar Abilowo, Astri Yulia Sari Lubis* \\ Prodi Diploma III Keperawatan Belitung, Poltekkes Kemenkes Pangkalpinang, Belitung, Indonesia \\ *E-mail: sarie.lubis21@gmail.com
}

Received: 29 Januari 2022

Accepted: 25 Februari 2022

Published: 28 Februari 2022

\begin{abstract}
The high prevalence of heart disease in Indonesia makes the introduction of Cardiopulmonary Resuscitation (CPR) to prevent worsening of the patient's condition before or after respiratory and cardiac arrest. Prevention is a series of efforts and anticipations that need to be considered before providing treatment for cardiac arrest or respiratory arrest. Prevention will give much better results than having to perform cardiopulmonary resuscitation. The purpose of this community service is to provide CPR education to youth in the Belitung Regency community by increasing the knowledge and skills of basic life support for ordinary people. The method in implementing this service goes through several stages, namely first, by reviewing the location to be addressed, taking care of licensing to the puskesmas and village office, and then conducting discussions with the puskesmas and village heads of Air Selumar and Pelepak Pute. The results after being given CPR education and practice with the demonstration method using phantom CPR, there was an increase in community knowledge by $86.7 \%$. Education about CPR is needed by the community to improve knowledge and basic life support skills for ordinary people.
\end{abstract}

Keywords: Education, Cardiopulmonary Resuscitation, Community.

\begin{abstract}
Abstrak
Prevalensi penyakit jantung di Indonesia yang cukup tinggi menjadikan pengenalan Resusitasi Jantung Paru (RJP) dapat dilakukan sebagai pencegahan memburuknya keadaan pasien sebelum atau sesudah terjadinya henti nafas dan henti jantung. Pencegahan merupakan serangkaian usaha maupun antisipasi yang perlu dipikirkan sebelum memberikan penanganan henti jantung atau henti nafas. Pencegahan akan memberikan hasil yang jauh lebih baik dari pada harus melakukan resusitasi jantung paru. Tujuan dari pengabdian masyarakat ini untuk memberikan edukasi RJP pada Pemuda di Masyarakat Kabupaten Belitung dengan peningkatan pengetahuan dan keterampilan bantuan hidup Dasar orang awam. Metode dalam pelaksanaan pengabdian ini melalui beberapa tahapan yaitu pertama, dengan meninjau lokasi yang akan dituju, mengurus perijinan ke puskesmas dan kantor desa, dan selajutnya melakukan diskusi dengan pihak puskesmas dan kepala desa Air Selumar dan Pelepak Pute. Hasil setelah diberikan edukasi dan praktik RJP dengan metode demonstrasi menggunakan phantom RJP terjadi peningkatan pengetahuan masyarakat sebesar $86,7 \%$. Edukasi tentang RJP diperlukan masyarakat untuk meningkatkan pengetahuan dan keterampilan bantuan hidup dasar orang awam.
\end{abstract}

Kata Kunci: Edukasi, Resusitasi Jantung Paru, Masyarakat. 


\section{A. PENDAHULUAN}

Prevalensi penyakit jantung di Indonesia pada tahun 2018 cukup tinggi dengan angka confidence interval 1,4-1,5\% $(95 \% \mathrm{Cl})$ pada jumlah sampel 1.017.290 orang (Badan Penelitian dan Pengembangan Kesehatan Kemenkes RI, 2019). Sedangkan prevalensi penyakit jantung di Provinsi Kepulauan Bangka Belitung pada tahun 2018 menunjukkan angka confidence interval 1,2$1,8 \%(95 \% \mathrm{Cl})$ dengan jumlah sampel 5.592 orang. Jenis kelamin perempuan secara nasional mendominasi dengan 1,6\% pada confidence interval 1,6-1,7\% (95\% Cl) dengan 506.576 responden. Sedangkan laki-laki ada pada angka 1,3\% \% pada confidence interval 1,3-1,4\% $(95 \% \mathrm{Cl})$ dengan 510.714 responden (Badan Penelitian dan Pengembangan kesehatan, 2019). Penyakit jantung adalah semua jenis penyakit jantung termasuk kelainan jantung bawaan yang didiagnosis oleh dokter.

Pengenalan Resusitasi Jantung Paru (RJP) dapat dilakukan sebagai pencegahan memburuknya keadaan pasien sebelum atau sesudah terjadinya henti nafas dan henti jantung. Pencegahan merupakan serangkaian usaha maupun antisipasi yang perlu dipikirkan sebelum memberikan penanganan henti jantung atau henti nafas. Pencegahan akan memberikan hasil yang jauh lebih baik dari pada harus melakukan resusitasi jantung paru (Kusumawati \& Jaya, 2019). Hasil survei pada masyarakat Kabupaten Belitung menunjukkan bahwa dari 80 warga terdapat 67 orang $(83,75 \%)$ tidak memahami tentang RJP dengan baik dan benar.

Kegawatdaruratan merupakan suatu kejadian yang tiba-tiba menuntut tindakan segera yang mungkin karena epidemic, kejadian alam, untuk bencana teknologi, perselisihan atau kejadian yang disebabkan manusia. Hasil penelitian yang dilakukan tentang Pelatihan Bantuan Hidup Dasar dengan Media Phantom Resusitasi jantung Paru (RJP) Meningkatkan Pengetahuan dan Keterampilan Bantuan Hidup Dasar Pada Orang Awam (Putri et al., 2019).

Permasalahan yang terjadi dalam kesehatan dunia saat ini adalah angka kematian yang terjadi di luar rumah sakit Out-of-Hospital Cardiac Arrest (OHCA) akibat henti jantung. Setiap tahunnya angka kejadiannya sangat tinggi dan meningkat. Keterlambatan dalam pelaporan dan pemberian tindakan Resusitasi Jantung Paru dapat mengakibatkan kematian. Dengan memberikan pengetahuan mengenai RJP diharapkan dapat mengurangi angka kematian akibat dari henti jantung. Hasil penelitian pengetahuan remaja tentang resusitasi jantung paru berhubungan dengan efikasi diri remaja di Malang menyebutkan bahwa tingkat pengetahuan mengenai RJP masih sangat rendah sehingga perlu diadakan kerjasama pelatihan RJP pada remaja (Yasin et al., 2020).

Penelitian lain telah dilakukan di Polda Jatim kepada anggota Brimob tentang efektifitas simulasi resusitasi jantung paru terhadap kemampuan penatalaksanaan resusitasi jantung paru anggota brimob. Hasil penelitian menunjukan seluruh Anggota Brimob memiliki kemampuan dengan kategori kurang terampil dalam melakukan resusitasi jantung paru sebelum dilakukan simulasi yaitu sebanyak $25(100 \%)$ responden, Hampir seluruh Anggota Brimob memiliki kemampuan dengan kategori terampil dalam melakukan resusitasi jantung paru setelah dilakukan simulasi yaitu sebanyak 22 (88,0\%) (Kusumawati \& Jaya, 2019).

Pengabdian masyarakat ini bertujuan untuk memberikan edukasi RJP pada masyarakat di Kabupaten Belitung dan meningkatnya pengetahuan dan keterampilan bantuan hidup dasar orang awam secara mandiri untuk menolong orang yang membutuhkan sehingga korban henti jantung bisa tertolong.

\section{B. METODE DAN PELAKSANAAN}

Pelaksanaan kegiatan pengabdian masyarakat dilakukan di wilayah kerja Puskesmas Sijuk, yaitu di Desa Air Selumar dan Pelepak Pute dengan beberapa tahapan yaitu pertama, dengan meninjau lokasi yang akan dituju, mengurus perijinan dan selanjutnya melakukan diskusi dengan pengurus wilayah dan puskesmas Sijuk agar kegiatan ini dapat berjalan dengan lancar. Tahapan selanjutnya adalah pelaksanaan kegiatan sosialisasi dan demonstrasi RJP dengan mematuhi protokol kesehatan pencegahan Covid -19.

Metode kegiatan pengabdian kepada masyarakat diawali dengan pretest pengukuran tingkat pengetahuan responden menggunakan kuesioner, pemaparan mengenai Resusitasi Jantung Paru 
(RJP), demonstrasi menggunakan phantom RJP, praktik RJP dan setelah itu dievaluasi menggunakan kuesioner yang sama saat pretest. Hasil pretest dan posttest akan dievaluasi kemudian. Materi pemaparan RJP berisi tentang Anatomi Fisiologi Jantung dan juga cara melakukan RJP pada saat pandemic Covid-19. Setelah pemaparan materi kemudian tim pengabdi dibantu mahasiswa mendemonstrasikan cara melakukan RJP pada saat pandemic Covid-19 dengan benar. Saat demonstrasi responden menyimak dengan seksama. Kemudian setelah itu responden diminta untuk mempraktikkan RJP pada saat pandemic Covid-19 secara berkelompok.

\section{HASIL DAN PEMBAHASAN}

Kegiatan pengabdian berjalan lancar yang dihadiri oleh 40 orang, yaitu dari Desa Pelepak Pute sebanyak 19 orang peserta dan di Desa Air Selumar sebanyak 21 orang peserta dengan mematuhi protokol kesehatan pencegahan Covid -19. Kegiatan ini diawali mengisi kuesioner pretest kemudian pemaparan materi berisi tentang Anatomi Fisiologi Jantung dan juga cara melakukan RJP pada saat pandemic Covid-19. Setelah pemaparan materi kemudian tim pengabdi dibantu mahasiswa mendemonstrasikan cara melakukan RJP pada saat pandemic Covid-19 dengan benar dilanjutkan simulasi berkelompok untuk mempraktikkan RJP pada saat pandemic Covid-19.

Tabel 1. Hasil pretest dan posttest

\begin{tabular}{lrrrrl}
\hline & $\mathrm{N}$ & Minimum & Maximum & Mean & Delta Mean \\
\hline Pretest & 40 & 31,25 & 87,5 & 69,23 & \multirow{2}{*}{8,56} \\
\hline Posttest & 40 & 50 & 100 & 77,79 & \\
\hline
\end{tabular}

Tabel 1 menunjukkan bahwa hasil kegiatan edukasi yang sudah dilakukan menunjukkan rata-rata nilai pretest adalah sebesar 69,23 dan mengalami peningkatan saat posttest menjadi 77,79. Hal ini menunjukkan bahwa terjadi kenaikan rata-rata pengetahuan peserta sebesar $8,56 \%$.

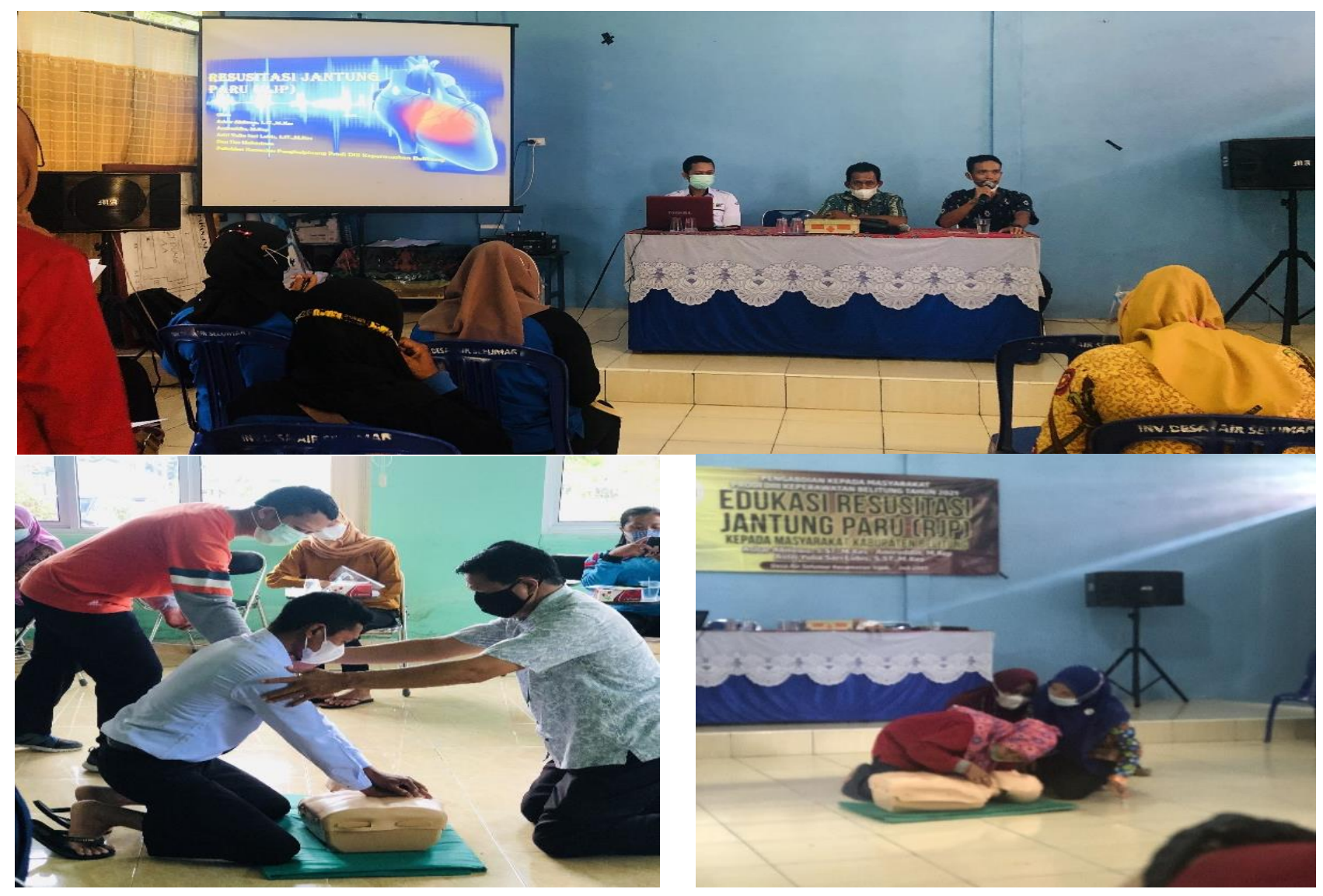



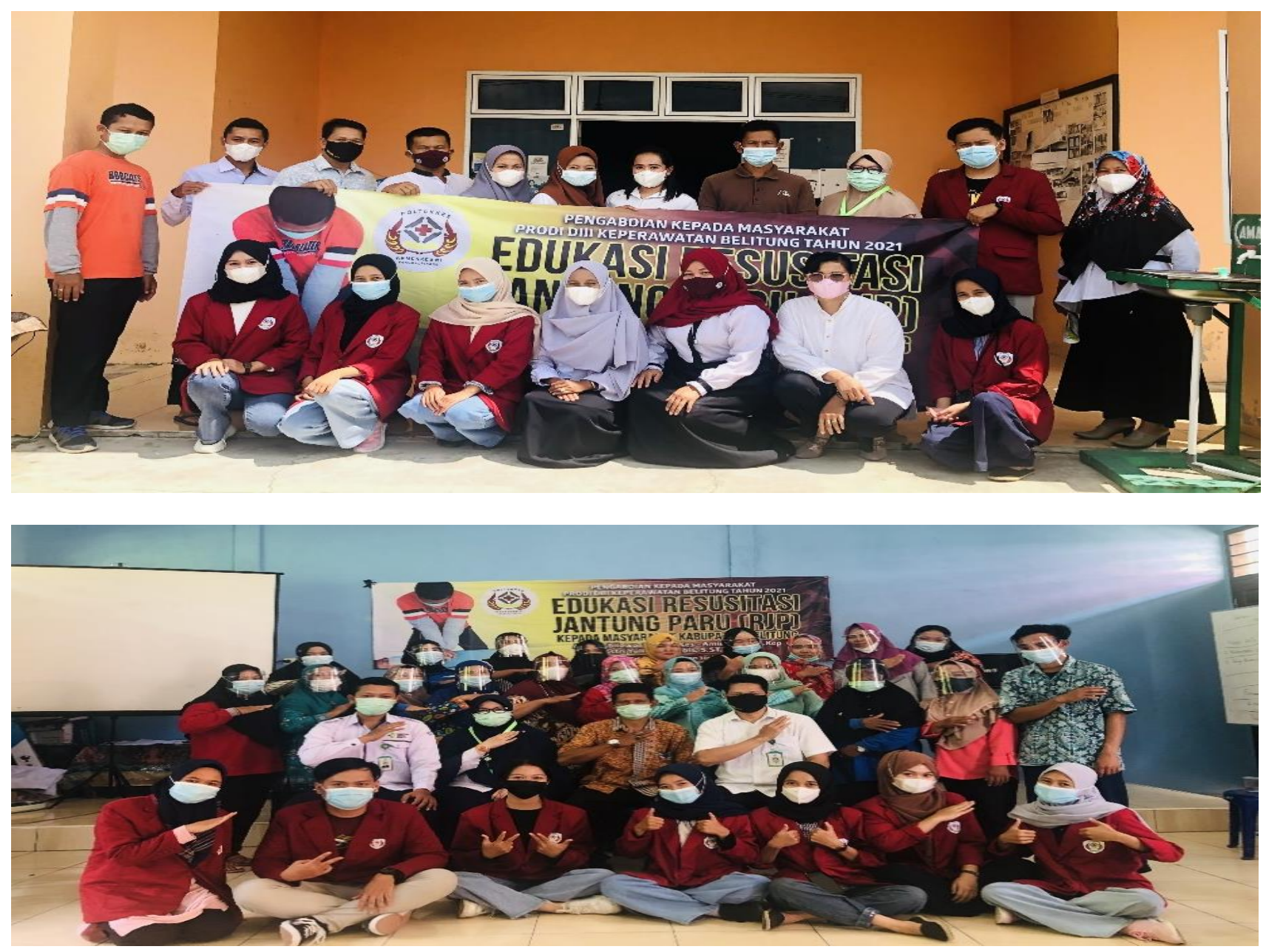

Gambar 1. Dokumentasi Pelaksanaan Kegiatan

Hasil pengabdian kepada masyarakat ini terjadi peningkatan pengetahuan responden setelah diberikan edukasi RJP dengan metode demonstrasi. Hasil kegiatan pengabdian yang dilakukan oleh tim didukung dengan evidence based hasil penelitian yang sudah dilakukan terkait dengan metode demonstrasi dapat meningkatkan kemampuan lifesaving pada Basic Life Support (BLS). Ada perbedaan efektivitas metode pendidikan kesehatan audiovisual dengan demonstrasi terhadap kemampuan lifesaving pada BLS, dimana kemampuan lebih meningkat dengan metode demonstrasi (Haryuni \& Sulistyawati, 2017).

Selain itu, hasil kegiatan pengabdian yang dilakukan oleh tim sejalan dengan beberapa kegiatan pengabdian berupa penyuluhan kesehatan tentang resusitasi jantung paru (RJP) dengan metode demonstrasi menggunakan phantom RJP yang menunjukkan ada peningkatan pengetahuan dan keterampilan tentang RJP. Phantom Resusitasi Jantung Paru (PREJARU) sebagai alat demonstrasi kepada responden dengan hasil yang menunjukkan bahwa ada pengaruh pelatihan bantuan hidup dasar dengan media Phantom Resusitasi Jantung Paru (PREJARU) dapat meningkatkan pengetahuan dan keterampilan bantuan hidup dasar orang awam (Putri et al., 2019).

Selain tentang RJP, edukasi yang dilakukan juga memberikan materi tentang Anatomi Fisiologi Jantung dan juga cara melakukan RJP pada saat pandemic Covid-19. Hal ini sejalan dengan kegiatan pengabdian yang dilakukan sebelumnya bahwa penyuluhan kesehatan tentang pengertian, tujuan, indikasi, dan prosedural RJP dapat meningkatkan pengetahuan dan pemahaman aparat pemerintah, kader Kesehatan, dan masyarakat Desa Sanrobone mengenai perbedaan kematian secara klinis dan kematian biologis, mengenali henti jantung dan henti napas (Sudarman \& Asfar, 2020). 
Hasil kegiatan ini juga disepakati ke depannya dapat dilaksanakan secara bergantian dari desa ke desa untuk dilakukan edukasi di wilayah kerja Puskesmas Sijuk dalam upaya untuk meningkatnya pengetahuan dan keterampilan bantuan hidup dasar orang awam secara mandiri untuk menolong orang yang membutuhkan sehingga korban henti jantung bisa tertolong. Selain penyuluhan kesehatan, tim pengabdian juga memberkan leafleat dan brosur kepada peserta. Hal ini dilakukan untuk menambah wawasan pengetahuan masyarakat agar bisa mendapatkan informasi terbaru terkait Resusitasi Jantung Paru (RJP) terutama saat masa pandemic Covid-19. Sejalan dengan kajian ilmiah sebelumnya yang menunjukkan bahwa penyuluhan, pemberian leaflet dan brosur juga dapat meningkatkan kesadaran dan perilaku seseorang (Yasin et al., 2020).

\section{KESIMPULAN}

Hasil kegiatan pengabdian kepada masyarakat setelah diberikan edukasi dan praktik RJP dengan metode demonstrasi menggunakan phantom RJP terjadi peningkatan pengetahuan masyarakat sebesar $86,7 \%$. Kegiatan pengabmas ini diikuti peserta dengan antusias dan berjalan lancar, sehingga edukasi tentang RJP ini dapat meningkatkan pengetahuan dan keterampilan bantuan hidup dasar orang awam terutama di saat pandemic Covid-19. Kegiatan edukasi RJP kepada warga Kabupaten Belitung diharapkan dapat dilaksanakan secara bergantian dari desa ke desa dan dimodifikasi dengan menambahkan materi lain yang dapat bermanfaat untuk warga, misalnya edukasi cara melakukan Pertolongan Pertama pada Kecelakaan (P3K) yang baik dan benar.

\section{UCAPAN TERIMA KASIH}

Puji syukur kepada Allah SWT atas terselesainya pengabdian masyarakat ini. Terimakasih kepada Poltekkes Kemenkes Pangkalpinang, Kepala Puskesmas Sijuk Kabupaten Belitung, dan Kepala Desa Air Selumar dan Pelepak Pute beserta staf yang telah memberikan izin dan masyarakat desa yang bersedia menjadi responden dalam pengabdian masyarakat ini.

\section{DAFTAR PUSTAKA}

Badan Penelitian dan Pengembangan kesehatan. (2019). Laporan Riskesdas Kepulauan Bangka Belitung 2018. Jakarta: Kemenkes RI.

Badan Penelitian dan Pengembangan Kesehatan Kemenkes RI. (2019). Laporan_Nasional_RKD2018_FINAL. Jakarta: Kemenkes RI.

Haryuni, S., \& Sulistyawati, W. (2017). Perbedaan Efektifitas Metode Pendidikan Kesehatan Basic Life Support (Bls) Audiovisual Dengan Demonstrasi Terhadap Kemampuan Life Saving Pada Mahasiswa Ilmu Keperawatan Fik Universitas Kadiri The Differences Of Effectiveness Of Health Education Method For Audiovisual Basic Life Support (Bls) With Demonstration Of Live Saving Ability To Students Of Nursing Science Fik Kadiri University. Journal of Nursing Care \& Biomolecular, 2(1), 2017-2048.

Kusumawati, P. D., \& Jaya, A. W. D. (2019). Efektifitas Simulasi Resusitasi Jantung Paru Terhadap Kemampuan Penatalaksanaan Resusitasi Jantung Paru Anggota Brimob. Jurnal IImiah IImu Keperawatan Indonesia, 9(04), 667-672. https://doi.org/10.33221/jiki.v9i04.355

Putri, P. R., Safitri, F. N., Munir, S., \& Hermawan, A. (2019). Pelatihan Bantuan Hidup Dasar Dengan Media Phantom Resusitasi Jantung Paru (Prejaru) Meningkatkan Pengetahuan Dan Keterampilan Bantuan Hidup Dasar Pada Orang Awam. Jurnal Gawat Darurat, 1, 7-12.

Sudarman, \& Asfar, A. (2020). Pelatihan Resusitasi Jantung Paru (Rjp) Bagi Aparat Pemerintah, Kader Kesehatan Dan Masyarakat Di Desa Sanrobone Kabupaten Takalar. https://doi.org/10.31604/jpm.v3i1.10-16

Yasin, D. D. F., Ahsan, \& Rahmawati, S. D. (2020). Pengetahuan Remaja Tentang Resusitasi Jantung Paru Berhubungan dengan Efikasi Diri Remaja di SMK Negeri 2 Singosari Malang. Care:Jurnal IImiah IImu Kesehatan, 8(1), 116-126. https://jurnal.unitri.ac.id/index.php/care/article/view/1751 